Note

\section{Radical Formation during the Processing of Green Tea}

\author{
Hisashi Yoshioka, Shinji Tsuyumu* \\ and Kenji TAKAYANAGI** \\ School of Pharmaceutical Science, \\ University of Shizuoka, 395 Yada, \\ Shizuoka 422, Japan \\ * Faculty of Agriculture, Shizuoka University, \\ 836 Ohya, Shizuoka 422, Japan \\ ** National Research Institute of Vegetables, \\ Ornamental Plants and Tea, 2769 Kanaya. \\ Shizuoka 428, Japan
}

Received June 5, 1989

Green tea has various ingredients that are pharmaceutically effective. ${ }^{1-3)}$ However, some of them seem to be labile, because processed products of tea leaves and their hot-water extracts change color by standing in the air. The color of fruits like pear and apple also turns to brown after wounding, and free radicals are formed in this process. ${ }^{4}$ In addition, treatment with an aqueous $\mathrm{NaCl}$ solution, which suppresses the browning reaction causes the appearance of an ESR signal of the divalent manganese ion. We report here that similar phenomena occur during the processing of green tea.

The process for manufacturing green tea is divided into six subprocesses as shown in Table I. Tea (cv. "Yabukita") sample at each stage of subprocessing were supplied by the National Research Institute of Vegetables, Ornamental Plants and Tea. The samples after each step of subprocessing were immediately cooled and then freeze-dried. The freeze-dried samples were crushed to the size of around $1 \mathrm{~mm}$ square in a mortar and packed in a polyethylene tube of $7 \mathrm{~mm}$ o.d. for ESR measurements. All the spectra were measured at room temperature and were recorded using a JEOL Model JES-3BS.X spectrometer (X-band) with a field modulation of $100 \mathrm{kHz}$.

ESR spectra of the samples after each subprocess are shown in Fig. 1. Two absorptions, a singlet at the center and a sextet, can be observed in all the samples. This sextet is very similar to the spectrum of the manganese ions in dormant spores of Bacillis megaterium $\mathrm{KM},{ }^{5,6)}$ which was analysed as a superposition of a sextet due to the $\mathrm{Mn}^{2+}$ ion and a very broad absorption caused by spin-exchange interaction. The hyperfine splitting constant and the $g$ value also indicate that the sextet is attributable to the $\mathrm{Mn}^{2+}$ ion. ${ }^{7)}$ On the other hand, the singlet is due to organic free radicals. The intensities of these absorptions are summarized on Table 1 with the air temperature and the time required for each subprocess. The signal intensity of the $\mathrm{Mn}^{2+}$ ion per dry weight was almost constant throughout the subprocesses. However, the intensity of the singlet increased with the progress of the process, except in the case of subprocess 3 in which the sample was not heated. These facts suggest that some fractions of the radicals were newly produced during processing. The intensity of the singlet increased further when the processed sample was dried for $1.5 \mathrm{hr}$ at $80^{\circ} \mathrm{C}$. It seems that the increase of the radical depended on the temperature of the air and on the water content. A considerable amount of free radicals had already formed by the end of the first subprocess.

In the previous paper, ${ }^{4)}$ we examined the browning of apple fruits and confirmed the formation of free radicals accompanying the browning due to the oxidation of polyphenols. In the case of tea processing, the color of the tea leaves is pale yellowish green at the end of the first subprocess, but it changes gradually into dark green with the progress of processing. This suggests that similar

Table I. Subprocesses and the Intensity of ESR Absorption of the Free Radical AND THE MANGANESE ION

\begin{tabular}{|c|c|c|c|c|c|}
\hline & \multirow{2}{*}{ Subprocess } & \multirow{2}{*}{ Air temperature } & \multirow{2}{*}{ Time required } & \multicolumn{2}{|c|}{ Intensity ${ }^{\dagger}$} \\
\hline & & & & Singlet & Broad sextet \\
\hline 1) & Steaming & Steam & $30 \mathrm{sec}$ & 0.37 & 1.17 \\
\hline 2) & Primary drying with rolling & $80^{\circ} \mathrm{C}$ & $40 \mathrm{~min}$ & 0.40 & 1.17 \\
\hline 3) & Tea rolling & Room temperature & $15 \mathrm{~min}$ & 0.34 & 1.02 \\
\hline 4) & Secondary drying with rolling & $38^{\circ} \mathrm{C}$ & $20 \mathrm{~min}$ & 0.52 & 0.96 \\
\hline 5) & Final drying with rolling & $100^{\circ} \mathrm{C}$ (pan temp.) & $11 \mathrm{~min}$ & 0.67 & 1.00 \\
\hline 6) & Tea drying & $60^{\circ} \mathrm{C}$ & $25 \mathrm{~min}$ & 1.00 & 1.00 \\
\hline & Heating in a dryer & $80^{\circ} \mathrm{C}$ & $1.5 \mathrm{hr}$ & 3.12 & 1.06 \\
\hline
\end{tabular}

$\dagger$ Intensity of each sample was first measured as the peak-to-peak height/dry weight, and then adjusted as the value relative to 6 . 


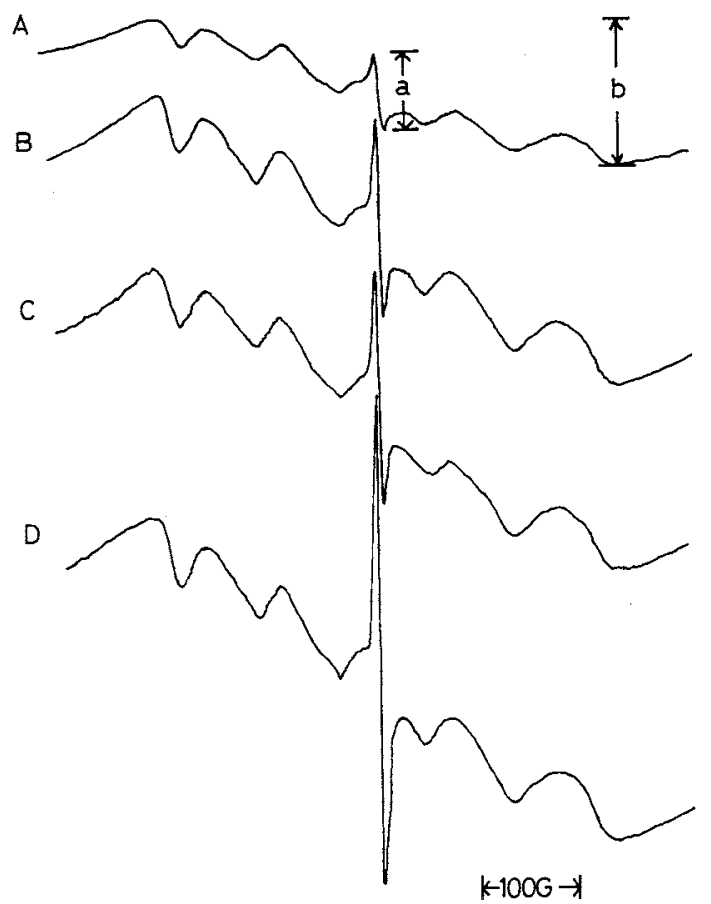

Fig. 1. ESR Spectra of the Tea Leaves after Each Subprocess.

$1, A ; 2, B ; 5, C ; 6, D$. a and $b$ are the peak to peak heights of the free radical and the manganese ion, respectively.

chemical changes to those of apple occur during tea processing. Polyphenois are usually oxidized enzymatically or automatically without enzymes. A considerable amounts of radicals had already been produced by the end of the subprocess 1 , although the time for treatment was very short compared with the other subprocesses, and freeze drying and crushing the sample seem not to have produced that were assumed from the case of the apple. ${ }^{4)}$ Therefore, it seems that the oxidation of polyphenols took place enzymatically before tea processing. However, most of the enzymes must be inactivated by steaming in subprocess 1 , so the formation of the radicals after that is attributed to the autooxidation of polyphenols at a high temperature.

In the case of the apple, treatment with $\mathrm{NaCl}$ solution in order to suppress the browning caused the appearance of an ESR absorption of the $\mathrm{Mn}^{2+}$ ion. ${ }^{4)}$ This spectrum for apple gave a far sharper sextet and was apparently different from the broad sextet shown in Fig. 1, so we examined the effect of a $\mathrm{NaCl}$ solution on tea. Tea leaves after subprocess 6 were dipped into a $10 \mathrm{wt} \%$ aqueous $\mathrm{NaCl}$ solution for a day at room temperature. Then, the leaves and the solution were freeze-dried together, and the spectrum was measured similarly to the former conditions of Fig. 1.

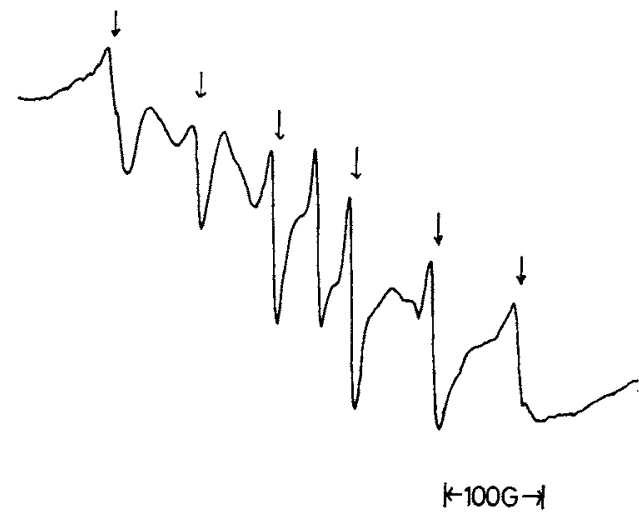

Fig. 2. ESR Spectrum of the Tea after Subprocess 6 as Treated with an Aqueous $\mathrm{NaCl}$ Solution.

Figure 2 shows the spectrum of the sample treated with the $\mathrm{NaCl}$ solution. It looks very complicated, but can be analysed as the overlap of a sharp sextet indicated with arrows and the background absorption similar to that in Fig. 1. The line shape of this sharp sextet is almost the same as that found in the spectrum of the apple treated with the $\mathrm{NaCl}$ solution. A tentative spectral simulation showed that the shape comes from the anisotropic $g$ value and the hyperfine splitting constant slightly deviated from the isotropic one. We consider that the $\mathrm{Mn}^{2+}$ ions responsible for the sharp sextet come from the manganese ions which existed in the processed tea at other stages. They seems to be produced in association with the process of radical formation, because the color of the tea leaves and the extract solution changed on standing in the air, but was suppressed in the $\mathrm{NaCl}$ solution.

The identification of the free radical, the $\mathrm{Mn}^{2+}$ ion of the original broad sextet, and the sharp one, as well as the relationship between them, are now under investigation.

\section{References}

1) T. Matsuzaki and Y. Hara, Nippon Nōgeikagaku Kaishi, 59, 129 (1985).

2) T. Kada, K. Kaneko, S. Matsuzaki, T. Matsuzaki and Y. Hara, Mutation Research, 150, 127 (1985).

3) Y. Hara, T. Matsuzaki and T. Suzuki, Nippon Nōgeikagaku Kaishi, 61, 803 (1987).

4) H. Yoshioka and S. Tsuyumu, Agric. Biol. Chem., 52, 2977 (1988).

5) J. J. Windle and L. E. Sacks, Biochim. Biophys. Acta, 66, 173 (1963).

6) K. Johnstone, C. S. A. B. Stewart, M. D. Barratt and D. J. Ellar, Biochim. Biophys. Acta, 714, 379 (1982).

7) "Landolt-Bönstein," Neue Serie, II/2, 8, 10, 11, Magnetic Properties of Transition Metal Compounds, Springer-Verlag, 1966, 1977, 1980, 1981. 